\title{
BMJ Open Association between neighbourhood walkability and metabolic risk factors influenced by physical activity: a cross-sectional study of adults in Toronto, Canada
}

\author{
C K Jennifer Loo, ${ }^{1}$ Michelle Greiver, ${ }^{2,3}$ Babak Aliarzadeh, ${ }^{2,3}$ Daniel Lewis ${ }^{4}$
}

To cite: Loo CKJ, Greiver M, Aliarzadeh B, et al. Association between neighbourhood walkability and metabolic risk factors influenced by physical activity: a cross-sectional study of adults in Toronto, Canada. BMJ Open 2017;7: e013889. doi:10.1136/ bmjopen-2016-013889

- Prepublication history and additional material is available. To view please visit the journal (http://dx.doi.org/ 10.1136/bmjopen-2016013889).

Received 16 August 2016 Revised 27 January 2017 Accepted 16 February 2017

CrossMark

For numbered affiliations see end of article.

Correspondence to Dr C K Jennifer Loo; jennifer.loo@mail.utoronto.ca

\section{ABSTRACT}

Objective: To determine whether neighbourhood walkability is associated with clinical measures of obesity, hypertension, diabetes and dyslipidaemia in an urban adult population.

Design: Observational cross-sectional study. Setting: Urban primary care patients.

Participants: 78023 Toronto residents, aged 18 years and over, who were formally rostered or had at least 2 visits between 2012 and 2014 with a primary care physician participating in the University of Toronto Practice Based Research Network (UTOPIAN), within the Canadian Primary Care Sentinel Surveillance Network (CPCSSN).

Main outcome measures: Differences in average body mass index (BMI), systolic and diastolic blood pressure, fasting blood glucose, haemoglobin A1C ( $\mathrm{HbA1C})$, total cholesterol, high-density lipoprotein (HDL), low-density lipoprotein and triglyceride between residents in the highest versus the lowest quartile of neighbourhood walkability, as estimated using multivariable linear regression models and stratified by age. Outcomes were objectively measured and were retrieved from primary care electronic medical records. Models adjusted for age, sex, smoking, medications, medical comorbidities and indices of neighbourhood safety and marginalisation.

Results: Compared with those in the lowest walkability quartile, individuals in the highest quartile had lower mean BMI $\left(-2.64 \mathrm{~kg} / \mathrm{m}^{2}, 95 \% \mathrm{Cl}-2.98\right.$ to $-2.30 ; p<0.001)$, systolic blood pressure $(-1.35 \mathrm{~mm} \mathrm{Hg}, 95 \% \mathrm{Cl}-2.01$ to $-0.70 ; p<0.001)$, diastolic blood pressure $(-0.60 \mathrm{~mm} \mathrm{Hg}, 95 \% \mathrm{Cl} 1.06$ to $-0.14 ; p=0.010)$ and $\mathrm{HbA} 1 \mathrm{C}(-0.063 \%, 95 \% \mathrm{Cl}$ -0.11 to $-0.021 ; p=0.003)$ and higher mean $\mathrm{HDL}$ (0.052 mmol/L, $95 \%$ Cl 0.029 to $0.075 ; p<0.001)$. In age-stratified analyses, differences in the mean BMI were consistently observed for adults aged 18 to under $40\left(-4.44 \mathrm{~kg} / \mathrm{m}^{2}, 95 \% \mathrm{Cl}-5.09\right.$ to $\left.-3.79 ; p<0.001\right)$, adults aged $40-65\left(-2.74 \mathrm{~kg} / \mathrm{m}^{2}, 95 \% \mathrm{Cl}-3.24\right.$ to $-2.23 ; p<0.001)$ and adults aged over $65(-0.87 \mathrm{~kg} /$ $\mathrm{m}^{2}, 95 \% \mathrm{Cl}-1.48$ to $\left.-0.26 ; \mathrm{p}=0.005\right)$.

Conclusions: There was a clinically meaningful association between living in the most walkable

\section{Strengths and limitations of this study}

- This neighbourhood walkability study is unique in examining a set of objectively measured metabolic risk factors, all of which are known to change with physical activity.

- We used electronic medical record data, which allowed us to control for patient-level covariates and express results in a clinically meaningful way.

- It was not possible to control for diet or the food environment with our study data.

- The cross-sectional study design could not rule out a residential selection effect in which individuals with healthier lifestyles may choose to reside in more walkable neighbourhoods.

neighbourhoods and having lower BMI in adults of all ages.

\section{INTRODUCTION}

Increasing physical activity can significantly impact disability-adjusted life years in developed countries. This is because many of the top risk factors associated with excess morbidity and mortality-high body mass index (BMI), high blood pressure, high glycaemic levels and high cholesterol-are all impacted by exercise. ${ }^{1}$ Clinical practice guidelines consistently recommend physical activity, as part of a healthy lifestyle ${ }^{2-4}$ and as nonpharmacological therapy for overweight and obesity, ${ }^{5-8}$ hypertension, ${ }^{9-11}$ diabetes ${ }^{12-14}$ and dyslipidaemia. ${ }^{15-17}$

At the population level, public health professionals have advocated for the use of built environment designs that support or promote active transportation such as utilitarian walking or cycling. ${ }^{18}{ }^{19}$ Utilitarian walking describes non-recreational walking 
that is used as a mode of transportation, commonly in the course of conducting errands, or travelling to and from school or work. ${ }^{20}{ }^{21}$ By recognising neighbourhood design as a way to influence health behaviours and 'build in' physical activity into daily living, this population health approach advances health promotion to sectors beyond healthcare, towards the creation of public policies and environments that support health. ${ }^{22}$

Multiple scales have been developed and validated to measure aspects of a neighbourhood's built environment that promote pedestrian walking. ${ }^{23}{ }^{24}$ Characteristics such as residential density, intersection density and public transport density have been shown to influence walkability and physical activity. ${ }^{25}$ Current evidence suggests that greater neighbourhood walkability is associated with increased physical activity, through walking for transport or utilitarian walking. ${ }^{26-31}$ Studies using survey or administrative data have found associations between areas of higher walkability and population-level health outcomes such as lower prevalence and incidence of obesity and diabetes, ${ }^{30}{ }^{32-34}$ and lower incidence of hypertension. ${ }^{35}$ However, there is limited information on objectively measured metabolic risk factors which are known to change with physical activity.

This study examined the association between relative residential neighbourhood walkability and objectively measured metabolic risk factors in an urban adult population.

\section{METHODS}

This study used an observational cross-sectional design and linked routinely collected electronic medical record (EMR) data with neighbourhood-level characteristics.

\section{Study population}

The study population included patients, aged 18 and above, seen by a primary care physician participating in the University of Toronto Practice Based Research Network (UTOPIAN). UTOPIAN is 1 of 11 Primary Care Practice Based Research Networks that are part of the Canadian Primary Care Sentinel Surveillance Network (CPCSSN). CPCSSN is a multidisease surveillance system where primary care physicians contribute deidentified EMR data to a national database. ${ }^{36}$ In Canada, universal access to primary care services is publicly funded, and in the province of Ontario, where Toronto is situated, 94\% of residents have a primary care provider. ${ }^{37}$ Patients who were enrolled with, or who had at least two visits with a CPCSSN-UTOPIAN primary care physician between 1 January 2012 and 31 December 2014 and who had a valid City of Toronto residential postal code were included in this study. Data were extracted as of 31 December 2014 using procedures previously described. ${ }^{36}$

\section{Measure of neighbourhood walkability}

The walkability of each individual's residential neighbourhood was measured using Walk Score, a validated index that calculates the walkability of an address based on distance to amenities and aspects of pedestrian friendliness, including population density, block length and intersection density. ${ }^{38}$ Increasing Walk Score has been linked to increased utilitarian walking and decreased obesity prevalence in Ontario, Canada. ${ }^{29}$ In this walkability index, locations are scored from 0 to 100 , where 100 is the most walkable. ${ }^{38}$ Toronto has 140 neighbourhoods, each of which is an administrative area that covers several city blocks, and has a minimum population of 7000-10000. ${ }^{39}$ Neighbourhood-level Walk Scores for all Toronto neighbourhoods are publicly available online ${ }^{40}$ and represent a population-weighted aggregation of a grid of Walk Score points for the entire area of a neighbourhood, as delineated by administrative boundaries. ${ }^{38}$ The Walk Scores current as of 2014 were retrieved. ${ }^{40}$ Based on their residential postal code, participants were assigned to a Toronto neighbourhood using Toronto neighbourhood and postal code area shapefiles ${ }^{41-43}$ with ESRI ArcGIS ArcMap V.10.1.

\section{Health outcome measures}

The health outcome measures in this study were BMI, systolic and diastolic blood pressure (sBP, dBP), fasting blood glucose (FBG), haemoglobin A1c (HbA1c), total cholesterol (TC), high-density lipoprotein (HDL), lowdensity lipoprotein (LDL) and triglyceride (TG). These measures were selected because they represent widely accepted indicators of obesity, hypertension, glycaemic control and dyslipidaemia, for which target ranges are well established in clinical practice guidelines. ${ }^{5-17}$ If multiple values were present between 2012 and 2014, the most recent record was used for data analysis. Given that the study sample was derived from a primary care patient population, the collection of these health measures represented the full spectrum of clinical testing: screening of healthy and at-risk individuals, diagnosis of individuals and monitoring of individuals with chronic conditions for disease control and therapy optimisation.

\section{Covariates}

Individual and neighbourhood-level covariates were measured. Individual health and sociodemographic characteristics obtained from CPCSSN-UTOPIAN data included key variables that can influence the clinical outcome measures of interest: patient age, sex, current smoking status, presence of a diagnosis of hypertension or diabetes and presence of a prescription for a weight-loss medication, an antihypertensive medication, an antidiabetic medication or a lipid-lowering medication. Diagnoses of hypertension and diabetes were based on validated CPCSSN case definitions and case-finding algorithms. ${ }^{44}$

Neighbourhood rates of violent crime reported to the Toronto Police Service (ie, assault, sexual assault, robbery and murder) were used as an indicator of neighbourhood safety, ${ }^{45}$ given the possibility that neighbourhood crime and perception of safety may influence 
utilitarian walking. ${ }^{21}$ Owing to the link between marginalisation and health, the Ontario Marginalization Index scores of Toronto neighbourhoods were also included as covariates. ${ }^{46} 47$ This index uses census data and assigns scores across four specific dimensions that contribute to the process of marginalisation. Material deprivation scores incorporated measures of unemployment, low income, low education and low-quality housing. Ethnic concentration scores accounted for recent immigration and self-identification as a visible minority. Residential instability scores were derived from multiple indicators, including the proportion of the population who had moved in the previous 5 years, and the proportion of dwellings that were not owned. Dependency scores included indicators measuring the proportion of the population aged 65 and older and the proportion of the population not participating in the labour force. ${ }^{46} 47$

\section{Statistical analyses}

Descriptive statistics were calculated for demographic variables, health outcome measures and all covariates. Toronto neighbourhood walkability was visualised with a choropleth map. Means and 95\% CIs of all health measures were calculated for the highest and lowest neighbourhood walkability quartiles and significance testing was performed on the unadjusted means using t-tests assuming equal variances. Multivariable linear regression models were also used to compare the mean health measures in the highest versus the lowest walkability quartile. All models were adjusted for covariates of age, sex, smoking status, neighbourhood rates of violent crime and neighbourhood indices of material deprivation, ethnic concentration, residential instability and dependency from the Ontario Marginalization Index. Models predicting BMI were also adjusted for the presence of a weight-loss medication. Models predicting blood pressure were adjusted for BMI, the presence of a hypertension diagnosis and prescription of antihypertensive medication. Models predicting HbAlc and FBG were adjusted for BMI, the presence of a diabetes diagnosis and prescription of antidiabetic medication. Models predicting cholesterol (TC, HDL, LDL, TG) were adjusted for BMI and the presence of a prescription for lipid-lowering medication. There were insufficient observations within each neighbourhood to use multilevel models. However, to ensure that the use of non-hierarchical linear regression was appropriate, intraclass correlation coefficients (ICCs) were calculated. Low ICCs for each health outcome (ICC $=0.050$ for BMI, ICC $<0.01$ for all other outcomes) revealed that very little of the total variance was accounted for by clustering within neighbourhoods, and that a non-hierarchical approach was reasonable.

Differences in health measures across walkability quartiles were examined for all ages, and in stratified analyses across three age subgroups of 18 to under 40 years, 4065 years and over 65 years. Broadly, these age categories represent segments of the population where primary versus secondary prevention strategies may be relevant in distinct ways. A younger adult population is more amenable to primary prevention of chronic disease. The primary and secondary prevention are relevant for middle-aged adults, and notably, they undergo lipid and diabetes screening as recommended by clinical practice guidelines. ${ }^{15} 48$ Finally, older adults may differ from younger adults due to increased medical comorbidities that affect the health markers of interest, and due to potentially decreased mobility that may affect levels of walking and physical activity.

All data were analysed using Stata IC/V.12.1 and mapping was carried out using ESRI ArcGIS ArcMap V.10.1.

\section{RESULTS}

A total of 78023 UTOPIAN patients met the inclusion criteria. The generation of the study sample is displayed in figure 1 .

Characteristics of the study sample are displayed in table 1. Residents of the lowest and highest quartiles of neighbourhood walkability were similar with respect to age, proportion of women and proportion of smokers. Neighbourhoods in the highest walkability quartile had higher violent crime rates, somewhat lower deprivation scores, but similar ethnic concentration compared with neighbourhoods in the lowest quartile. A map of Toronto's 140 neighbourhoods and their Walk Scores is displayed in figure 2. The most walkable neighbourhoods were concentrated in Toronto's downtown core. Neighbourhood Walk Scores ranged from 42 to 99.

Unadjusted means and 95\% CIs for all health measures in the lowest and highest quartiles of neighbourhood walkability are displayed in table 2 . All differences in unadjusted means were significant at the $p<0.001$ level.

Table 3 displays the adjusted linear regression coefficients comparing differences in the mean health measures between the highest and lowest quartiles of neighbourhood walkability. Data for all quartiles are reported in online supplementary table S1. After adjusting for covariates, there were statistically significant differences in average measures of BMI, sBP, dBP, HbA1c and HDL between participants in the highest versus the lowest walkability quartile.

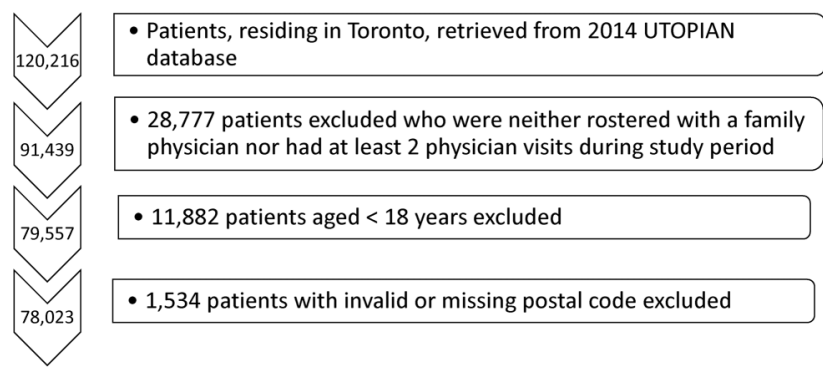

Figure 1 Sequence of steps in generation of study sample. 


\begin{tabular}{|c|c|c|c|c|c|c|c|c|c|}
\hline \multirow[b]{2}{*}{ Characteristic } & \multicolumn{3}{|c|}{ Lowest quartile of neighbourhood walkability } & \multicolumn{3}{|c|}{$\begin{array}{l}\text { Highest quartile of neighbourhood } \\
\text { walkability }\end{array}$} & \multicolumn{3}{|c|}{ Total study population } \\
\hline & $\begin{array}{l}\text { Frequency } \\
(\%)\end{array}$ & Mean (SD) & $\begin{array}{l}\mathrm{N} \text { patients with } \\
\text { data }\end{array}$ & $\begin{array}{l}\text { Frequency } \\
(\%)\end{array}$ & Mean (SD) & $\begin{array}{l}N \text { patients with } \\
\text { data }\end{array}$ & $\begin{array}{l}\text { Frequency } \\
\text { (\%) }\end{array}$ & Mean (SD) & $\begin{array}{l}\mathrm{N} \text { patients with } \\
\text { data }\end{array}$ \\
\hline Sex (female) & 11303 & $(62.3 \%)$ & 18137 & $11399(62.7 \%)$ & & 18192 & $\begin{array}{l}48556 \\
(62.2 \%)\end{array}$ & & 78022 \\
\hline Age (years) & & $49.2(19.2)$ & 18122 & & 48.5 (17.9) & 18180 & & $50.0(19.2)$ & 77966 \\
\hline $18 \leq$ age $<40$ & $6448(35.6 \%)$ & & & $6895(37.9 \%)$ & & & $\begin{array}{l}26977 \\
(34.6 \%)\end{array}$ & & \\
\hline $40<$ age $\leq 65$ & $7731(42.7 \%)$ & & & $7760(42.7 \%)$ & & & $\begin{array}{l}33056 \\
(42.4 \%)\end{array}$ & & \\
\hline$>65$ years & $3943(21.8 \%)$ & & & $3525(19.4 \%)$ & & & $\begin{array}{l}17933 \\
(23.0 \%)\end{array}$ & & \\
\hline Smoking (current smoker) & $1530(12.0 \%)$ & & 12772 & $1669(13.3 \%)$ & & 12511 & $6808(12.1 \%)$ & & 56093 \\
\hline \multicolumn{10}{|l|}{ Anthropometric indicators } \\
\hline Body mass index (BMI) $\left(\mathrm{kg} / \mathrm{m}^{2}\right)$ & & $29.6(10.0)$ & 9819 & & $26.0(6.22)$ & 10920 & & $27.2(7.4)$ & 46029 \\
\hline Overweight or obese $\left(\mathrm{BMl} \geq 25 \mathrm{~kg} / \mathrm{m}^{2}\right)$ & $6370(64.9 \%)$ & & 9819 & $5505(50.4 \%)$ & & 10920 & $\begin{array}{l}26309 \\
(57.2 \%)\end{array}$ & & 46029 \\
\hline Prescribed weight-loss medication & $1146(6.3 \%)$ & & 18137 & $523(2.9 \%)$ & & 18192 & $3387(4.3 \%)$ & & 78023 \\
\hline \multicolumn{10}{|l|}{ Blood pressure control } \\
\hline Hypertension diagnosis & $4068(22.4 \%)$ & & 18137 & $2980(16.4 \%)$ & & 18192 & $\begin{array}{l}16241 \\
(20.8 \%)\end{array}$ & & 78023 \\
\hline Prescribed antihypertensive medication & $4796(26.4 \%)$ & & 18137 & $3555(19.5 \%)$ & & 18192 & $\begin{array}{l}19020 \\
(24.4 \%)\end{array}$ & & 78023 \\
\hline Systolic blood pressure (sBP) (mm Hg) & & $121.5(16.0)$ & 13722 & & $117.4(15.5)$ & 13950 & & $119.8(16.0)$ & 59634 \\
\hline Diastolic blood pressure (dBP) $(\mathrm{mm} \mathrm{Hg})$ & & $75.0(10.0)$ & 13722 & & $73.1(10.0)$ & 13950 & & $73.8(10.0)$ & 59634 \\
\hline \multicolumn{10}{|l|}{ Blood glucose control } \\
\hline Diabetes diagnosis & $2242(12.4 \%)$ & & 18137 & $1096(6.0 \%)$ & & 18192 & $6988(9.0 \%)$ & & 78023 \\
\hline Prescribed antidiabetic medication & $1788(9.9 \%)$ & & 18137 & $786(4.3 \%)$ & & 18192 & $5220(6.7 \%)$ & & 78023 \\
\hline Haemoglobin A1c (HbA1c) (\%) & & $6.10(1.10)$ & 6721 & & $5.74(0.75)$ & 5570 & & $5.89(0.88)$ & 29575 \\
\hline Fasting blood glucose (FBG) (mmol/L) & & $5.56(1.70)$ & 8388 & & $5.32(1.26)$ & 6367 & & $5.42(1.46)$ & 34698 \\
\hline \multicolumn{10}{|l|}{ Lipid control } \\
\hline Prescribed lipid-lowering medication & & $3686(20.3 \%)$ & 18137 & $2453(13.5 \%)$ & & 18192 & $\begin{array}{l}13979 \\
(17.9 \%)\end{array}$ & & 78023 \\
\hline Total cholesterol (TC) (mmol/L) & & $4.73(1.08)$ & 8690 & & $4.93(1.04)$ & 6825 & & $4.81(1.06)$ & 36498 \\
\hline High-density lipoprotein (HDL) (mmol/L) & & $1.43(0.41)$ & 8844 & & $1.58(0.47)$ & 7014 & & $1.49(0.44)$ & 37295 \\
\hline Low-density lipoprotein (LDL) (mmol/L) & & $2.71(0.90)$ & 8770 & & $2.78(0.88)$ & 6983 & & $2.74(0.89)$ & 37097 \\
\hline Triglycerides (TG) (mmol/L) & & $1.34(1.05)$ & 8883 & & $1.26(0.79)$ & 7008 & & $1.31(0.87)$ & 37417 \\
\hline $\begin{array}{l}\text { Neighbourhood violent crime rate* } \\
\text { (events/10 } 000 \text { residents) }\end{array}$ & & $95.4(49.8)$ & 18137 & & $128.2(84.3)$ & 18192 & & $91.3(59.6)$ & 78023 \\
\hline Neighbourhood instability score $†$ & & $-0.048(0.48)$ & 18137 & & $1.37(0.68)$ & 18192 & & $0.480(0.71)$ & 78023 \\
\hline Neighbourhood deprivation score $\dagger$ & & $0.30(0.96)$ & 18137 & & $-0.53(0.69)$ & 18192 & & $-0.170(0.77)$ & 78023 \\
\hline Neighbourhood ethnic concentration score $†$ & & $1.78(0.89)$ & 18137 & & $0.82(0.89)$ & 18192 & & $1.353(1.08)$ & 78023 \\
\hline Neighbourhood dependency score $†$ & & $-0.020(0.36)$ & 18137 & & $-0.44(0.27)$ & 18192 & & $-0.100(0.39)$ & 78023 \\
\hline
\end{tabular}

$\mathrm{N}$, number of observations in study sample.

*Violent crime includes occurrences of assault, sexual assault, robbery and murder.

†Scores of neighbourhood instability, deprivation, ethnic concentration and dependency are dimensions of the Ontario Marginalization Index. ${ }^{49}$ Scores are population-weighted, and higher values indicate greater instability/deprivation/ethnic concentration/dependency. 
Figure 2 Map of Toronto neighbourhood walkability as measured by neighbourhood Walk Scores. Walk Scores for Toronto neighbourhoods $(n=140)$ were retrieved from the City of Toronto Open Data Catalogue. ${ }^{40}$

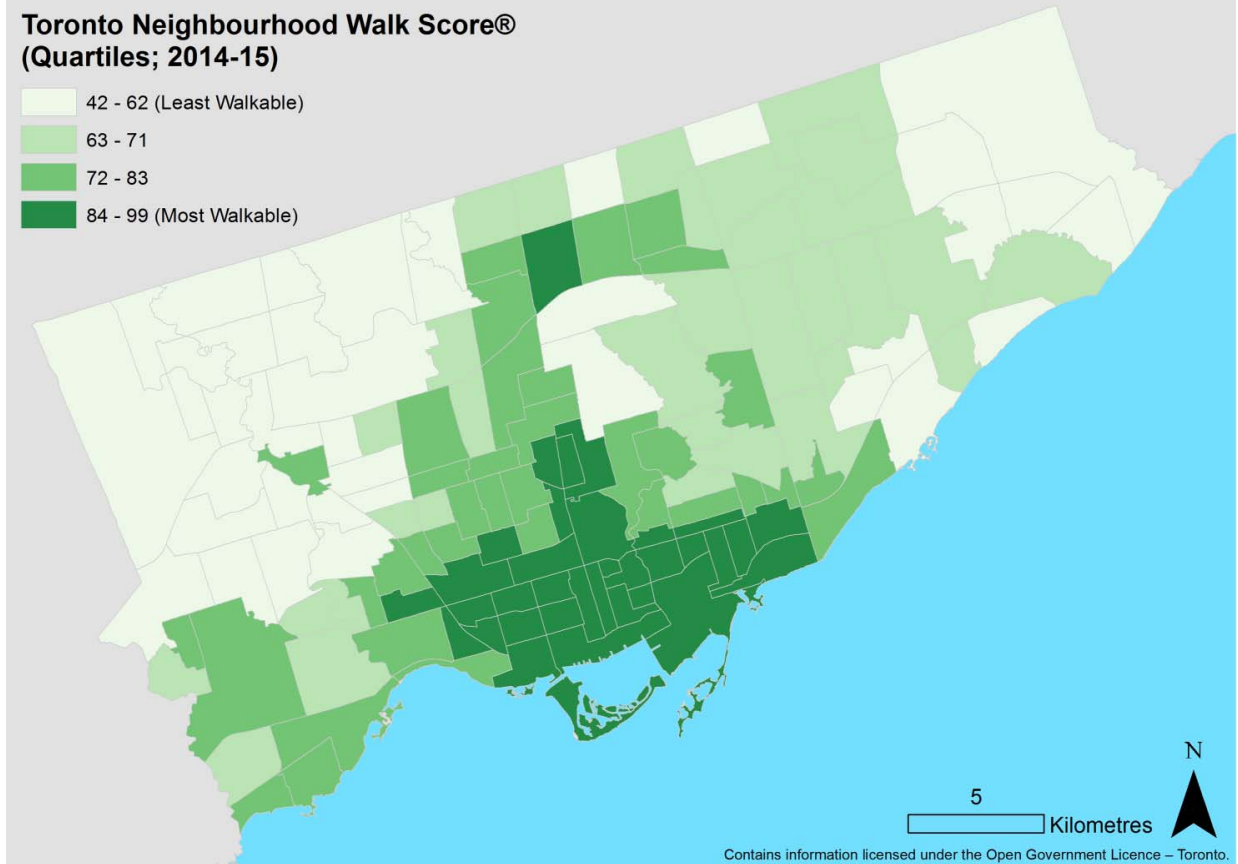

Table 2 Unadjusted means and 95\% Cls for health measures in the lowest and highest quartiles of neighbourhood walkability

\begin{tabular}{|c|c|c|}
\hline Health measure (unit) & $\begin{array}{l}\text { Mean }(95 \% \mathrm{Cl}) \text { in lowest quartile of } \\
\text { neighbourhood walkability }\end{array}$ & $\begin{array}{l}\text { Mean }(95 \% \mathrm{Cl}) \text { in highest quartile } \\
\text { of neighbourhood walkability }\end{array}$ \\
\hline Body mass index (BMI) $\left(\mathrm{kg} / \mathrm{m}^{2}\right)$ & 29.6 (29.5 to 29.8$)$ & $26.0(25.9 \text { to } 26.2)^{\star}$ \\
\hline Systolic blood pressure (sBP) (mm Hg) & $121.5(121.2$ to 121.7$)$ & $117.4(117.2 \text { to } 117.7)^{\star}$ \\
\hline Diastolic blood pressure (dBP) (mm Hg) & $75.0(74.8$ to 75.1$)$ & $73.1(72.9 \text { to } 73.3)^{\star}$ \\
\hline Haemoglobin A1c (HbA1c) (\%) & 6.10 (6.08 to 6.12$)$ & $5.74(5.72 \text { to } 5.76)^{\star}$ \\
\hline Fasting blood glucose (FBG) (mmol/L) & 5.56 (5.53 to 5.59$)$ & $5.32(5.28 \text { to } 5.35)^{\star}$ \\
\hline Total cholesterol (TC) (mmol/L) & $4.73(4.71$ to 4.75$)$ & $4.93(4.91 \text { to } 4.96)^{*}$ \\
\hline High-density lipoprotein (HDL) (mmol/L) & 1.43 (1.42 to 1.44$)$ & $1.58(1.57 \text { to } 1.59)^{\star}$ \\
\hline Low-density lipoprotein (LDL) (mmol/L) & 2.71 (2.69 to 2.73$)$ & $2.78(2.76 \text { to } 2.80)^{\star}$ \\
\hline Triglycerides (TG) (mmol/L) & 1.34 (1.32 to 1.36$)$ & $1.26(1.24 \text { to } 1.28)^{\star}$ \\
\hline
\end{tabular}

The mean BMI was $2.64 \mathrm{~kg} / \mathrm{m}^{2}$ lower $(95 \%$ CI -2.98 to $-2.30, \mathrm{p}<0.001)$ among individuals in the highest versus the lowest neighbourhood walkability quartile. In the stratified analyses, this difference was greatest in those aged 18 to under 40, where the mean BMI was $-4.44 \mathrm{~kg} / \mathrm{m}^{2}$ lower (95\% CI -5.09 to $\left.3.79, \mathrm{p}<0.001\right)$, and smallest in those over age 65 , where the mean BMI was $0.87 \mathrm{~kg} / \mathrm{m}^{2}$ lower $(95 \% \mathrm{CI}-1.48$ to $-0.26, \mathrm{p}=0.005)$.

When comparing average blood pressure measurements of individuals in the highest versus the lowest walkability quartile, the mean sBP was $1.35 \mathrm{~mm} \mathrm{Hg}$ lower (95\% CI -2.01 to $-0.70, \mathrm{p}<0.001)$ and the mean $\mathrm{dBP}$ was $0.60 \mathrm{~mm} \mathrm{Hg}$ lower $(95 \% \mathrm{CI}-1.06$ to $-0.14, \mathrm{p}=0.010)$. When stratifying by age categories, significant differences in the mean sBP and dBP were observed only in those aged 40-65.

With respect to blood glucose control, the mean HbA1c was $0.063 \%$ lower $(95 \%$ CI -0.11 to-0.021, $\mathrm{p}=0.003$ ) in those within the highest neighbourhood walkability quartile compared with those in the lowest quartile. After age stratification, a statistically significant difference was only present in those aged 18 to under 40. No evidence of differences in the mean FBG was observed between the highest and the lowest quartiles of neighbourhood walkability.

In terms of cholesterol parameters, the mean HDL was $0.052 \mathrm{mmol} / \mathrm{L}$ higher $(95 \%$ CI 0.029 to $0.075, \mathrm{p}<0.001)$ in those in the highest versus the lowest neighbourhood walkability quartile. Across the age subgroups, a significant difference in the mean HDL was present only in the two older age categories. The difference observed in the mean TC was of borderline statistical significance, and in the stratified analyses, was only significant in those aged 40-65. No strong evidence of differences in other cholesterol parameters was apparent. 
Table 3 Adjusted linear regression coefficients comparing differences in the mean health measures between the highest and lowest quartiles of neighbourhood walkability

\begin{tabular}{|c|c|c|}
\hline Health measure (unit) & Regression coefficient ( $95 \% \mathrm{Cl}$ ) & p Value \\
\hline BMI $\left(\mathrm{kg} / \mathrm{m}^{2}\right)$-all ages $\geq 18$ & $-2.64(-2.98$ to -2.30$)$ & $<0.001$ \\
\hline $18 \leq$ age $<40$ & $-4.44(-5.09$ to -3.79$)$ & $<0.001$ \\
\hline $40 \leq$ age $\leq 65$ & $-2.74(-3.24$ to -2.23$)$ & $<0.001$ \\
\hline Age $>65$ & $-0.87(-1.48$ to -0.26$)$ & 0.005 \\
\hline sBP $(\mathrm{mm} \mathrm{Hg})$-all ages $\geq 18$ & $-1.35(-2.01$ to -0.70$)$ & $<0.001$ \\
\hline $18 \leq$ age $<40$ & $-0.64(-1.68$ to 0.41$)$ & 0.23 \\
\hline $40 \leq$ age $\leq 65$ & $-1.97(-2.91$ to -1.03$)$ & $<0.001$ \\
\hline Age $>65$ & $-0.64(-2.14$ to 0.85$)$ & 0.40 \\
\hline $\mathrm{dBP}(\mathrm{mm} \mathrm{Hg})$-all ages $\geq 18$ & $-0.60(-1.06$ to -0.14$)$ & 0.010 \\
\hline $18 \leq$ age $<40$ & $0.12(-0.68$ to 0.93$)$ & 0.76 \\
\hline $40 \leq$ age $\leq 65$ & $-1.30(-1.94$ to -0.66$)$ & $<0.001$ \\
\hline Age $>65$ & $-0.19(-1.13$ to 0.75$)$ & 0.69 \\
\hline $\mathrm{HbA1c}(\%)$-all ages $\geq 18$ & $-0.063(-0.11$ to -0.021$)$ & 0.003 \\
\hline $18 \leq$ age $<40$ & $-0.12(-0.23$ to -0.019$)$ & 0.021 \\
\hline $40 \leq$ age $\leq 65$ & $-0.059(-0.12$ to 0.0026$)$ & 0.060 \\
\hline Age $>65$ & $-0.013(-0.078$ to 0.051$)$ & 0.69 \\
\hline FBG $(\mathrm{mmol} / \mathrm{L})$-all ages $\geq 18$ & $0.030(-0.038$ to 0.099$)$ & 0.39 \\
\hline $18 \leq$ age $<40$ & $-0.086(-0.24$ to 0.073$)$ & 0.29 \\
\hline $40 \leq$ age $\leq 65$ & 0.028 (-0.068 to 0.12$)$ & 0.57 \\
\hline Age $>65$ & $0.083(-0.036$ to 0.20$)$ & 0.17 \\
\hline $\mathrm{TC}(\mathrm{mmol} / \mathrm{L})$-all ages $\geq 18$ & 0.061 (0.00025 to 0.12$)$ & 0.049 \\
\hline $18 \leq$ age $<40$ & $-0.023(-0.18$ to 0.13$)$ & 0.77 \\
\hline $40 \leq$ age $\leq 65$ & $0.11(0.024$ to 0.19$)$ & 0.012 \\
\hline Age $>65$ & $-0.023(-0.13$ to 0.078$)$ & 0.65 \\
\hline $\mathrm{HDL}(\mathrm{mmol} / \mathrm{L})$-all ages $\geq 18$ & $0.052(0.029$ to 0.075$)$ & $<0.001$ \\
\hline $18 \leq$ age $<40$ & $0.022(0.038$ to 0.081$)$ & 0.47 \\
\hline $40 \leq$ age $\leq 65$ & $0.052(0.020$ to 0.084$)$ & 0.001 \\
\hline Age $>65$ & 0.060 (0.019 to 0.10$)$ & 0.004 \\
\hline LDL (mmol/L) —all ages $\geq 18$ & $0.010(-0.041$ to 0.062$)$ & 0.69 \\
\hline $18 \leq$ age $<40$ & $-0.0088(-0.14$ to 0.12$)$ & 0.89 \\
\hline $40 \leq$ age $\leq 65$ & $0.026(-0.044$ to 0.096$)$ & 0.47 \\
\hline Age $>65$ & $-0.036(-0.12$ to 0.049$)$ & 0.41 \\
\hline Triglyceride (mmol/L) —all ages $\geq 18$ & $-0.0031(-0.053$ to 0.047$)$ & 0.90 \\
\hline $18 \leq$ age $<40$ & $-0.14(-0.33$ to 0.047$)$ & 0.14 \\
\hline $40 \leq$ age $\leq 65$ & $0.038(-0.029$ to 0.11$)$ & 0.27 \\
\hline Age $>65$ & $-0.041(-0.11$ to 0.033$)$ & 0.28 \\
\hline
\end{tabular}

Results are presented for all ages and for each age subcategory. Regression coefficients represent differences in the mean health measure, adjusting for covariates of age, sex, current smoking status, BMI (except in the model where BMI is the health outcome measure) relevant medications and medical diagnoses, neighbourhood violent crime rates and neighbourhood indices of material deprivation, ethnic concentration, dependency and residential instability.

\section{DISCUSSION}

Key findings: neighbourhood walkability and metabolic risk factors

We observed an association between higher neighbourhood walkability and objectively measured metabolic risk factors. The magnitude of differences observed for BMI across all age groups and for blood pressure in middle-aged adults was clinically significant and relevant for population health.

\section{Strengths and limitations}

The main strength of this study is that it used EMR data to examine a set of clinical measures known to change with physical activity, all of which were objectively measured through physical examination or laboratory testing. The study controlled for individual clinical attributes as well as neighbourhood-level covariates that could have confounded the relationship between neighbourhood walkability and the metabolic risk factors of interest. ${ }^{28} 325051$

Overall, the study population included a large and diverse sample of adults of all ages, with and without chronic disease. However, the application of the study findings to other adult populations in a developed, urban setting should also consider that these were primary care patients. In particular, the study population did not include children or adolescents, had more older adults and had a greater proportion of women than the general population of Toronto. ${ }^{52}$ With respect to major comorbidities, the prevalence of hypertension and diabetes in the study sample $(20.8 \%$ and $9.0 \%$, respectively) were comparable to the prevalence of these 
diseases in the general population of Toronto $(22.7 \%$ and $10.4 \%$, respectively). ${ }^{53}{ }^{54}$ The study sample had a higher prevalence of overweight or obesity of $57.2 \%$ compared with the published Toronto prevalence of $45.8 \%{ }^{53}$ This may be related to the fact that the latter value is from self-reported population survey data, which is prone to under-reporting of BMI. ${ }^{55}$ National estimates that use directly measured BMI yield an overweight or obesity prevalence of $62 \% .^{56}$ Given that CPCSSN is the first multidisease, EMR-based surveillance system in Canada, further work would be of interest to characterise the sociodemographic and health attributes of participating patient populations, especially in relation to the general population.

The main limitation of this study is its cross-sectional nature, which precludes the establishment of temporality in the association between neighbourhood walkability and health outcomes. Importantly, it is not possible to rule out a residential selection effect, in which healthier individuals who choose to engage in more healthpromoting behaviours, such as physical activity, may also choose to live in more walkable areas to facilitate their preferred lifestyle. In other studies that either controlled for neighbourhood self-selection or were longitudinal in design, significant associations were still observed between neighbourhood walkability and levels of overweight or obesity. ${ }^{57} 58$ This study did not control for leisure physical activity, which may also influence the measured clinical outcomes, but-unlike utilitarian walking-is not thought to be a key mediator of the putative health benefits of walkable built environments. ${ }^{20} 212959$ Based on a recent study in Ontario, Canada, which found that differences in leisure physical activity were not significant between individuals from areas of varying walkability, ${ }^{29}$ any significant confounding by leisure physical activity would have biased results towards the null and led to underestimation of effects in the present study. Dietary information could not be captured in a valid manner using EMR data in this study. It is possible that dietary habits, particularly as linked to the food environment, may differ between neighbourhoods of high versus low walkability, ${ }^{60}{ }^{61}$ but the extent to which this may have affected estimates in this study is unclear. Similarly, this study did not control for major disabilities or mobility limitations which may have precluded engagement in utilitarian walking in affected participants. This may have contributed to the attenuation of differences in the mean BMI observed in older adults. Future work that controls for mobility limitations would be of interest to better explore the effects of neighbourhood walkability in older populations, particularly given that an association between walkability and physical activity has been previously reported in adults aged 65 and older. ${ }^{62}$

\section{Findings in relation to other studies}

The BMI findings are consistent with several recent studies which demonstrated lower prevalence of obesity in high-walkability neighbourhoods compared with lowwalkability neighbourhoods. ${ }^{29} 3033{ }^{34}$ Importantly, this study quantified the magnitude of the mean difference in BMI that was observed $\left(2.64 \mathrm{~kg} / \mathrm{m}^{2}\right)$, and found that this clinically meaningful difference varied across three age categories. In a previous longitudinal study of 701 participants, residential relocation involving a 10-point increase in street address Walk Score was associated with an average within-individual BMI reduction of $0.06 \mathrm{~kg}$ / $\mathrm{m}^{2} .{ }^{57}$ The magnitude of this effect was smaller than the $2.64 \mathrm{~kg} / \mathrm{m}^{2}$ difference in the mean BMI that was observed in this study, between the highest and lowest neighbourhood walkability quartiles (a difference of about 20-60 points in aggregate neighbourhood Walk Score). Importantly, the scale at which walkability was measured in the present study was at the larger neighbourhood level, rather than at the level of each resident's individual address. This has interesting implications for determining the spatial scale at which a built environment might exert positive health effects mediated by walkability and utilitarian physical activity.

With respect to blood pressure, one previous study that measured walkability and fast-food outlet density reported an association with blood pressure decreases in older adults, ${ }^{60}$ while another study found no association between walkability and self-reported hypertension. ${ }^{34}$ The effect size of aerobic exercise on blood pressure reduction has been reported as $-3.84 \mathrm{~mm} \mathrm{Hg}$ for $\mathrm{sBP}$ and $-2.58 \mathrm{~mm} \mathrm{Hg}$ for $\mathrm{dBP}^{63}$ Thus, it is plausible that the small differences in the mean sBP and $\mathrm{dBP}$ in the current study may be attributable to differences in levels of utilitarian walking. In the age-stratified analyses, only adults aged 40-65 demonstrated a significant difference in the mean sBP and dBP. In Canada, the age-specific prevalence of hypertension follows an S-shaped curve, with a prevalence of $5.7 \%$ in adults aged $35-39$, which rises steadily from $9.3 \%$ in adults aged $40-44$ to $53.6 \%$ in adults aged $65-69 .^{64}$ The lack of association in younger adults may be related to insufficient power in this study to detect blood pressure differences where hypertension prevalence is low. Alternatively, an association between walkable neighbourhoods and blood pressure may not exist or be relevant in younger adults, for which the incidence and risk of hypertension is already quite low $(<1 \%$ incidence in Canadians under 40 years of age). ${ }^{64}$ In older adults, potential explanations for a lack of an association include decreased mobility and ability to engage in utilitarian walking, or the possibility that physical activity effects on blood pressure become relatively insignificant in the context of multiple medications and comorbidities in this age group.

Although previous studies have found an association between neighbourhood walkability and both the prevalence and incidence of diabetes, ${ }^{30} 3233$ associations between neighbourhood walkability and HbA1c have not been reported. In a systematic review and meta-analysis of 23 RCTs, structured aerobic exercise durations of $150 \mathrm{~min}$ or less per week were found to be associated 
with $\mathrm{HbA1c}$ reductions of $0.36 \%{ }^{65}$ The observed difference in the mean HbAlc in this study was considerably smaller. This suggests that the level of physical activity potentially promoted by a more walkable neighbourhood may not be strongly associated with clinically significant changes to HbAlc. Another possibility is that the observed relationship between neighbourhood walkability and the mean $\mathrm{HbAlc}$ may have been confounded by variations in individual diet as well as in the larger food environment. Furthermore, given that neighbourhood walkability is associated with BMI and obesity prevalence, both of which influence the risk of diabetes, this may explain the finding of higher incidence and prevalence of diabetes in higher walkability neighbourhoods, rather than simply an independent effect of walkability on diabetes.

An association between neighbourhood walkability and objective cholesterol parameters has not been previously reported in the peer-reviewed literature. One previous study reported a lack of an association between walkability and self-reported hypercholesterolaemia. ${ }^{34}$ In a Cochrane review of exercise effects on overweight or obesity, an HDL improvement of $0.06 \mathrm{mmol} / \mathrm{L}$ was found among those who engaged in moderate aerobic exercise compared with controls with no treatment. ${ }^{66}$ This suggests that, in the current study, the observed difference in the mean HDL between the highest and lowest neighbourhood walkability quartiles is of a magnitude that could be plausibly attributed to a physical activity effect. The lack of consistent differences in other cholesterol parameters between the highest and lowest walkability quartiles is not incompatible with the literature. Indeed, a review of 51 studies, including 28 RCTs, of the effect of aerobic exercise training on blood lipids found that an increase in HDL was the most frequently observed outcome, and reductions in TC, LDL and TG were less commonly seen. ${ }^{67}$ Again, the current study did not control for dietary factors, which are known to influence cholesterol parameters, ${ }^{68}$ and the observed associations should be interpreted with this in mind.

\section{Implications of findings for population health}

From a clinical perspective, recognising the relative walkability of a patient's residential neighbourhood may aid health providers in making context-appropriate physical activity recommendations for health maintenance and chronic disease management. More importantly, the implications for walkable environments as a public health intervention are significant if the health associations for walkability presented in this and other studies represent a truly causal relationship. In other words, a highly walkable neighbourhood could represent a population-wide intervention capable of conferring multiple benefits related to obesity prevention, blood pressure control and potentially even blood glucose and lipid control. At the population level, even small changes in average BMI or blood pressure have the potential to 'shift the curve' with respect to the population distribution of disease risk. By lowering the average level of risk factors, such a population strategy targets the determinants of disease incidence and may have the capacity to prevent a considerable fraction of obesity, hypertension, diabetes and cardiovascular disease that is attributed to physical inactivity. ${ }^{69} 70$

One final issue of relevance for policymakers is that of equity. This study demonstrated that across 140 neighbourhoods within a single city, variations in health existed based on walkability characteristics of the built environment. Addressing the determinants of health and health equity at the population level should therefore include built environment considerations, such as access to public transportation and safe pedestrian infrastructure.

\section{CONCLUSIONS}

There is a clinically meaningful association between living in a neighbourhood in the highest walkability quartile and having lower BMI and modestly lower blood pressure. This study demonstrates that EMR data can be a source of objective clinical measures for population health research. Further longitudinal studies on walkable environments are needed to provide a realistic estimate of the magnitude and distribution of their health effects on the population, and to clarify the spatial scale at which neighbourhood walkability realises these effects. Further research is also needed to examine the broader health and non-health impacts of walkable neighbourhoods, particularly if they are implemented as a built environment intervention at the population level.

\section{Author affiliations}

${ }^{1}$ Dalla Lana School of Public Health, University of Toronto, Toronto, Ontario, Canada

${ }^{2}$ Department of Family and Community Medicine, University of Toronto,

Toronto, Ontario, Canada

${ }^{3}$ North York General Hospital, Toronto, Ontario, Canada

${ }^{4}$ Department of Social and Environmental Health Research, Faculty of Public Health and Policy, London School of Hygiene and Tropical Medicine, London, UK

Contributors CKJL conceptualised the study. CKJL and DL designed the analyses in consultation with MG and BA. CKJL cleaned and analysed the data, and drafted the manuscript. All authors contributed to revising the paper.

Funding This research received no specific grant from any funding agency in the public, commercial or not-for-profit sectors.

\section{Competing interests None declared.}

Ethics approval This study was reviewed and approved by the Canadian Primary Care Sentinel Surveillance Network (CPCSSN) Research, Privacy and Ethics Officer and by the London School of Hygiene and Tropical Medicine MSc Research Ethics Committee.

Provenance and peer review Not commissioned; externally peer reviewed.

Data sharing statement No additional data are available.

Open Access This is an Open Access article distributed in accordance with the Creative Commons Attribution Non Commercial (CC BY-NC 4.0) license, which permits others to distribute, remix, adapt, build upon this work noncommercially, and license their derivative works on different terms, provided the original work is properly cited and the use is non-commercial. See: http:// creativecommons.org/licenses/by-nc/4.0/ 


\section{REFERENCES}

1. Institute for Health Metrics and Evaluation. Global Burden of Disease. GBD Compare I Viz Hub. 2013.

2. Tremblay MS, Warburton DER, Janssen I, et al. New Canadian physical activity guidelines. Appl Physiol Nutr Metab 2011;36:36-46.

3. Department of Health. UK Physical Activity Guidelines. 2011.

4. US Department of Health and Human Services. 2008 Physical Activity Guidelines for Americans. 2008.

5. Brauer P, Connor Gorber S, Shaw E, et al. Recommendations for prevention of weight gain and use of behavioural and pharmacologic interventions to manage overweight and obesity in adults in primary care. CMAJ 2015;187:184-95.

6. Obesity. Identification, Assessment and Management of Overweight and Obesity in Children, Young People and Adults: Partial Update of CG43. London: National Clinical Guideline Centre, 2014

7. Jensen MD, Ryan DH, Apovian CM, et al. 2013 AHA/ACC/TOS guideline for the management of overweight and obesity in adults: a report of the American College of Cardiology/American Heart Association Task Force on Practice Guidelines and The Obesity Society. Circulation 2014;129(25 Suppl 2):S102-38.

8. Moyer VA. Screening for and management of obesity in adults: US Preventive Services Task Force recommendation statement. Ann Intern Med 2012;157:373-8.

9. Daskalopoulou SS, Rabi DM, Zarnke KB, et al. The 2015 Canadian hypertension education program recommendations for blood pressure measurement, diagnosis, assessment of risk, prevention, and treatment of hypertension. Can J Cardiol 2015;31:549-68.

10. James PA, Oparil S, Carter BL, et al. 2014 evidence-based guideline for the management of high blood pressure in adults: report from the panel members appointed to the Eighth Joint National Committee (JNC 8). JAMA 2014;311:507-20.

11. McCormack T, Krause T, O'Flynn N. Management of hypertension in adults in primary care: NICE guideline. $\mathrm{Br} J$ Gen Pract 2012;62:163-4.

12. Canadian Diabetes Association Clinical Practice Guidelines Expert Committee. Canadian Diabetes Association 2013 clinical practice guidelines for the prevention and management of diabetes in Canada. Can J Diabetes 2013;37(Suppl 1).

13. National Institute for Health and Care Excellence (NICE). Type 2 diabetes in adults: management 2015.

14. American Diabetes Association. (4) Foundations of care: education, nutrition, physical activity, smoking cessation, psychosocial care and immunization. Diabetes Care 2015;38(Suppl 1):S20-30.

15. Anderson TJ, Grégoire J, Hegele RA, et al. 2012 update of the Canadian Cardiovascular Society guidelines for the diagnosis and treatment of dyslipidemia for the prevention of cardiovascular disease in the adult. Can J Cardiol 2013;29:151-67.

16. Stone NJ, Robinson JG, Lichtenstein AH, et al. 2013 ACC/AHA guideline on the treatment of blood cholesterol to reduce atherosclerotic cardiovascular risk in adults: a report of the American College of Cardiology/American Heart Association Task Force on Practice Guidelines. J Am Coll Cardiol 2014;63:2889-934. doi: 10.1016/j.jacc.2013.11.002 (published Online First)

17. National Institute for Health and Care Excellence (NICE). Cardiovascular disease: risk assessment and reduction, including lipid modification. National Institute for Health and Care Excellence, 2014.

18. National Institute for Health and Care Excellence (NICE). Physical activity and the environment. Public health guideline. National Institute for Health and Care Excellence, 2008.

19. Mowat D, Gardner C, McKeown D, et al. Improving health by design in the Greater Toronto-Hamilton Area. A Report of Medical Officers of Health in the GTHA. 2014.

20. Saelens BE, Handy SL. Built environment correlates of walking: a review. Med Sci Sports Exerc 2008;40(Suppl 7):S550.

21. Sugiyama $T$, Neuhaus $M$, Cole $R$, et al. Destination and route attributes associated with adults' walking: a review. Med Sci Sports Exerc 2012;44:1275-86.

22. The Ottawa Charter for Health Promotion. First International Conference on Health Promotion, 21 November 1986. Ottawa.

23. Duncan DT, Aldstadt J, Whalen J, et al. Validation of walk score for estimating neighborhood walkability: an analysis of four US metropolitan areas. Int J Environ Res Public Health 2011;8:4160-79.

24. Glazier RH, Weyman JT, Creatore Ml, et al. Development and validation of an urban walkability index for Toronto, Canada. Toronto Community Health Profiles Partnership. 2012.

25. Sallis JF, Cerin E, Conway TL, et al. Physical activity in relation to urban environments in 14 cities worldwide: a cross-sectional study. Lancet 2016;387:2207-17.
26. Freeman L, Neckerman K, Schwartz-Soicher O, et al. Neighborhood walkability and active travel (walking and cycling) in New York City. $\checkmark$ Urban Health 2013;90:575-85

27. Thielman J, Rosella L, Copes R, et al. Neighborhood walkability: differential associations with self-reported transport walking and leisure-time physical activity in Canadian towns and cities of all sizes. Prev Med 2015;77:174-80.

28. Arvidsson D, Eriksson U, Lonn SL, et al. Neighborhood walkability, income, and hour-by-hour physical activity patterns. Med Sci Sports Exerc 2013;45:698-705.

29. Chiu M, Shah BR, Maclagan LC, et al. Walk Score and the prevalence of utilitarian walking and obesity among Ontario adults: a cross-sectional study. Health Rep 2015;26:3-10.

30. Glazier RH, Creatore MI, Weyman JT, et al. Density, destinations or both? A comparison of measures of walkability in relation to transportation behaviors, obesity and diabetes in Toronto, Canada. PLOS ONE 2014;9:e85295.

31. Hajna S, Ross NA, Joseph L, et al. Neighbourhood walkability, daily steps and utilitarian walking in Canadian adults. BMJ Open 2015;5: e008964.

32. Booth GL, Creatore MI, Moineddin R, et al. Unwalkable neighborhoods, poverty, and the risk of diabetes among recent immigrants to Canada compared with long-term residents. Diabetes Care 2013;36:302-8.

33. Creatore MI, Glazier RH, Moineddin R, et al. Association of neighborhood walkability with change in overweight, obesity, and diabetes. JAMA 2016;315:2211-20.

34. Müller-Riemenschneider F, Pereira G, Villanueva K, et al. Neighborhood walkability and cardiometabolic risk factors in Australian adults: an observational study. BMC Public Health 2013;13:1-9.

35. Chiu M, Rezai MR, Maclagan LC, et al. Moving to a highly walkable neighborhood and incidence of hypertension: a propensity-score matched cohort study. Environ Health Perspect 2016;124:754-60. doi:10.1289/ehp.1510425

36. Birtwhistle R, Keshavjee K, Lambert-Lanning A, et al. Building a pan-Canadian primary care sentinel surveillance network: initial development and moving forward. J Am Board Fam Med 2009;22:412-22.

37. Health Quality Ontario. Quality in Primary Care: Setting a foundation for monitoring and reporting in Ontario. Toronto: Queen's Printer for Ontario, 2015

38. Walk Score. Walk Score Methodology. 2015. https://www.walkscore. com/methodology.shtml.

39. City of Toronto. Neighbourhood Profiles. 2015. http://www1.toronto. $\mathrm{ca} / \mathrm{wps} /$ portal/contentonly?vgnextoid=ae17962c8c3f0410Vgn VCM10000071d60f89RCRD\&vgnextchannel=1e68f40f9aae0410Vgn VCM10000071d60f89RCRD.

40. Social Development Finance \& Administration. Wellbeing TorontoCivics \& Equity Indicators. 17 December. 2014. http://www1.toronto. $\mathrm{ca} / \mathrm{wps} /$ portal/contentonly?vgnextoid=906580ece073b410Vgn VCM10000071d60f89RCRD\&vgnextchannel=75d6e03bb8d1e 310VgnVCM10000071d60f89RCRD.

41. Social Development Finance \& Administration, City of Toronto. Boundaries of City of Toronto Neighbourhoods. 2014. http://www1. toronto.ca/wps/portal/contentonly?vgnextoid=04b489fe9c18b210Vgn VCM1000003dd60f89RCRD\&vgnextchannel=75d6e03bb8d1e310 VgnVCM10000071d60f89RCRD.

42. Statistics Canada. Postal Code Conversion File (PCCF) Reference Guide: June 2013 postal codes. Catalogue no. 92-154-G. Statistics Canada, 2013.

43. Statistics Canada. Forward Sortation Area Boundary File, Reference Guide: Census year 2011. Catalogue no. 92-179-G. Statistics Canada, 2011

44. Williamson T, Green ME, Birtwhistle R, et al. Validating the 8 CPCSSN case definitions for chronic disease surveillance in a primary care database of electronic health records. Ann Fam Med 2014;12:367-72.

45. Friesen D, Rajagopalan P, Strashin J. Toronto Crime by Neighbourhood. 15 April 2015. 2011. http://www.cbc.ca/toronto/ features/crimemap/.

46. Toronto Community Health Profiles Partnership. DA \& CT ON-Marg Data, 2006. 2006

47. Toronto Community Health Profiles Partnership. Ontario Marginalization Index (ON-Marg). 2015. http://www. torontohealthprofiles.ca/onmarg.php

48. Ekoé JM, Punthakee Z, Ransom T, et al. Screening for type 1 and type 2 diabetes. Can J Diabetes 2013;37(Suppl 1):S12-15. doi: 10.1016/j.jcjd.2013.01.012 
49. Matheson FI, Dunn J, Smith KLW, et al. Ontario Marginalization Index. User Guide Version 1.0. Toronto: Centre for Research on Inner City Health, 2012.

50. Manaugh K, El-Geneidy A. Validating walkability indices: how do different households respond to the walkability of their neighborhood? Transp Res D Transp Environ 2011;16:309-15

51. Carr LJ, Dunsiger SI, Marcus BH. Walk score ${ }^{\mathrm{TM}}$ as a global estimate of neighborhood walkability. Am J Prev Med 2010;39:460-3.

52. City of Toronto, City Planning Social Policy Analysis \& Research. 2011 census: age and sex counts. Toronto: City of Toronto, 2012

53. City of Toronto. Toronto Health Indicators-A Comparative Look. 2014. http://www1.toronto.ca/wps/portal/contentonly? vgnextoid=d69e6032bcaa6410VgnVCM10000071d60f89RCRD

54. Toronto Community Health Profiles Partnership. Age-Standardized Hypertension Prevalence Rate (\%) among Adults 20+. 2012. http:// www.torontohealthprofiles.ca/a_documents/TM_allCateg_maps/TM_ maps_AHD/3_AHD_HBP_All_MF_N_2012_20plus_NB.pdf

55. Connor Gorber S, Tremblay M, Moher D, et al. A comparison of direct vs. self-report measures for assessing height, weight and body mass index: a systematic review. Obes Rev 2007;8:307-26.

56. Statistics Canada. Canadian health measures survey: household and physical measures data, 2012 to 2013. The Daily: Statistics Canada, 2013.

57. Hirsch JA, Diez Roux AV, Moore KA, et al. Change in walking and body mass index following residential relocation: the multi-ethnic study of atherosclerosis. Am J Public Health 2014;104: e49-56.

58. Sallis JF, Saelens BE, Frank LD, et al. Neighborhood built environment and income: examining multiple health outcomes. Soc Sci Med 2009;68:1285-93.

59. McCormack GR, Shiell A. In search of causality: a systematic review of the relationship between the built environment and physical activity among adults. Int $J$ Behav Nutr Phys Act 2011;8:125.
60. Li F, Harmer P, Cardinal BJ, et al. Built environment and changes in blood pressure in middle aged and older adults. Prev Med 2009;48:237-41.

61. Mayne SL, Auchincloss AH, Michael YL. Impact of policy and built environment changes on obesity-related outcomes: a systematic review of naturally occurring experiments. Obes Rev 2015;16:362-75.

62. Berke EM, Koepsell TD, Moudon AV, et al. Association of the built environment with physical activity and obesity in older persons. $\mathrm{Am}$ J Public Health 2007;97:486-92.

63. Whelton SP, Chin A, Xin X, et al. Effect of aerobic exercise on blood pressure: a meta-analysis of randomized, controlled trials. Ann Intern Med 2002;136:493-503.

64. Robitaille C, Dai S, Waters C, et al. Diagnosed hypertension in Canada: incidence, prevalence and associated mortality. CMAJ 2012;184:E49-56.

65. Umpierre D, Ribeiro PA, Kramer CK, et al. Physical activity advice only or structured exercise training and association with $\mathrm{HbA1c}$ levels in type 2 diabetes: a systematic review and meta-analysis. JAMA 2011;305:1790-9.

66. Shaw K, Gennat H, O'Rourke P, et al. Exercise for overweight or obesity. Cochrane Database Syst Rev 2006;(4):CD003817.

67. Leon AS, Sanchez OA. Response of blood lipids to exercise training alone or combined with dietary intervention. Med Sci Sports Exerc 2001;33(Suppl 6):S502-15.

68. Third Report of The National Cholesterol Education Program (NCEP) Expert Panel on Detection, Evaluation, and Treatment of High Blood Cholesterol in Adults (Adult Treatment Panel III) final report. Circulation 2002;106:3143-421.

69. Lee IM, Shiroma EJ, Lobelo F, et al. Impact of physical inactivity on the world's major non-communicable diseases. Lancet 2012;380:219-29.

70. Rose G. Sick individuals and sick populations. Int J Epidemiol 2001;30:427-32. 